\title{
COMPARISON OF THE VISUALLY EVOKED RESPONSE IN DRUG-FREE CHRONIC SCHIZOPHRENIC PATIENTS AND NORMAL CONTROLS ${ }^{1}$
}

\author{
EDWARD F. DOMINO, SANDRA DEMETRIOU, THOMAS TUTTLE ${ }^{2}$ and VALERIE KLINGE \\ Departments of Pharmacology and Psychology, The Lafayette Clinic, Detroit, Mich. 48207 and \\ University of Michigan, Ann Arbor, Mich. 48109 (U.S.A.)
}

(Accepted for publication: May 15, 1978)

Following Ciganek's (1961) classic description of the human scalp EEG response to photic stimulation, considerable research has been devoted to this subject. Of special interest to clinical neurophysiologists as well as psychiatrists is whether psychiatric patients show abnormalities in the visual evoked response (VER) as well as other sensory evoked potentials. The extensive studies in this area have been reviewed by Shagass (1975). With particular attention to the visual evoked response in schizophrenics versus normals, Shagass $(1975,1976)$ reported that the VER of schizophrenics shows greater amplitude variability, faster latencies and less afterrhythm. Furthermore, chronic schizophrenics vary to a greater extent from normals than from acute or latent schizophrenics. In addition, Shagass and Schwartz (1965) and Shagass et al. (1977) have emphasized that the late components (beyond $100 \mathrm{msec}$ ) of the VER are reduced in amplitude in chronic schizophrenic patients. Shagass and Straumanis (1978) have concluded that antipsychotic medication tends to normalize the VER in patients who are clinically improved. Itil et al. (1972) have shown, using digital computer period analysis and analog power spectra, that

\footnotetext{
1 Supported in part by a grant from the State of Michigan to the Lafayette Clinic for schizophrenia research.

2 Present address: Wayne State University School of Medicine, Detroit, Michigan 48202.

Address requests for reprints to: Reprint Secretary, Lafayette Clinic, 951 E. Lafayette, Detroit, Mich. 48207, U.S.A.
}

schizophrenic patients show less amplitude variability than normal subjects. These findings are reminiscent of those of Murphree et al. (1962) and Goldstein et al. $(1963,1965)$ who found, using EEG recordings, that chronic schizophrenics were 'hyperaroused', and exhibited less variability than mentally normal controls.

The indole hypothesis of schizophrenia suggests that a hallucinogenic agent may be present in some schizophrenic patients. Animal data (Evarts 1958; Moore et al. 1976) have shown that the indole hallucinogens block the lateral geniculate nucleus of the cat and monkey. In a series of human studies, several investigators (Murphree et al. 1962; Goldstein et al. 1963; Rodin and Luby 1966; Itil 1977) reported LSD and other indolecontaining hallucinogens caused a reduction of the amplitude and lowered variance of the EEG and VER in normal subjects. In view of these studies, one would anticipate that the VER wave amplitudes of patients having an endogenous hallucinogenic substance are depressed. In fact, Rodin et al. (1968) have shown that some chronic schizophrenic patients have a diminished VER.

Gottlieb and Frohman (1974) reported that schizophrenics could be divided into two subgroups based on their blood tryptophan uptake level. The high tryptophan uptake schizophrenics (HT) also had a high lactate/ pyruvate ratio which indicates insufficient cellular oxidation, while the low tryptophan uptake schizophrenics (LT) had a low lactate/ 
pyruvate ratio. Rodin (1971) observed that HT uptake schizophrenic patients tended to have longer latencies and decreased amplitudes in their VER while LT schizophrenics exhibited the opposite tendencies (particularly with regard to amplitudes). He concluded that these subgroups must be analyzed separately or they will tend to cancel each other and 'normalize' their overall response curves.

We have had an opportunity to utilize a unique computer approach to analyze the VER of normals versus drug-free chronic schizophrenic patients as a group and dividing their HT and LT uptake subgroups according to Gottlieb and Frohman (1974). This manuscript describes the results obtained which do not support the hypothesis of a circulating hallucinogenic factor that depresses the VER of schizophrenic patients unless one also postulates that these patients are tolerant ${ }^{3}$.

\section{Methods}

Eleven normal male volunteers and 13 cooperative male drug-free chronic schizophrenics were studied. No significant differences were found between the two groups in height, weight, eye conditions, smoking habits, handedness, or education; however, the mean age for the patients was 35 , while the normai control group's age was $28(P<$ 0.05 ). All of the patients were fasting while 7 of the 11 normals had nad some form of breakfast. The average number of years of hospitalization for the chronic schizophrenics was 9 years. Because these patients were norcesponders to neuroleptic medication and the possible danger of developing tardive dyskinesia, all medication was stopped for at least 6 months prior to the study. Each parient was given the Brief Psychiatric Rating Scale (BPRS) on the day of the experiment which was then correlated with a ward token

\footnotetext{
3 Our original abstract (Domino et al., 1976) contained several errors which have been corrected in this publication.
}

system to measure the patient's current psychopathology.

The subject's head was measured and electrodes were applied using the 10-20 system for electrode placement (Cooper et al. 1971). Silver disc electrodes were used with Grass electrode cream. Data were gathered from $\mathrm{O}_{\mathrm{z}}, \mathrm{O}_{1}, \mathrm{O}_{2}, \mathrm{C}_{3}$ and $\mathrm{C}_{4}$ electrodes paired with combined ear reference $\left(A_{1}\right.$ and $\left.A_{2}\right)$. In all cases the resistance was checked on an ohm meter with each lead showing no greater than $10,000 \Omega$. The subject sat with closed eyes in a dark soundproof room with the face of a parabolic Grass PS-2 photic stimulator lamp of $5 \mathrm{in}$. diameter centered $15 \mathrm{~cm}$ from the nasion. Prior to photic stimulation, a $10 \mathrm{~min}$ resting record was obtained to determine the basic frequency characteristics of the subject's EEG. The subject's fixation on the stimulus was monitored by infrared, closed circuit television to insure his cooperation throughout. Several patients' records were not used because they could not keep their eyes closed or control their eye movements.

The stimulus used to obtain the VER results described in this manuscript was an unpatterned flash of single intensity. The experimental design followed in general the procedure of Kooi and Bagchi (1964) who also elicited the VER from flashes of light of the same intensity. This procedure seemed reasonable since Hall et al. (1973) used multiple flash intensities and found close agreement in the occipital latencies reported by Kooi and Bagchi (1964).

The Grass photic stimulator was set at low intensity $2\left(2.38 \times 10^{6}\right.$ lumens/sec $)$ for 3 separate runs: one real run, then a blind run in which a black cover was placed over the strobe lamp, and finally another real run. Each run contained a summation of 200 responses randomized from 1 to $3 \mathrm{sec}$. The analysis period ranged from $100 \mathrm{msec}$ prior to the flash to $400 \mathrm{msec}$ after the flash. To avoid habituation, the subject was allowed to relax for $5 \mathrm{~min}$ between runs.

The auditory click of the photic stimulator lamp was deadened by packing the back 


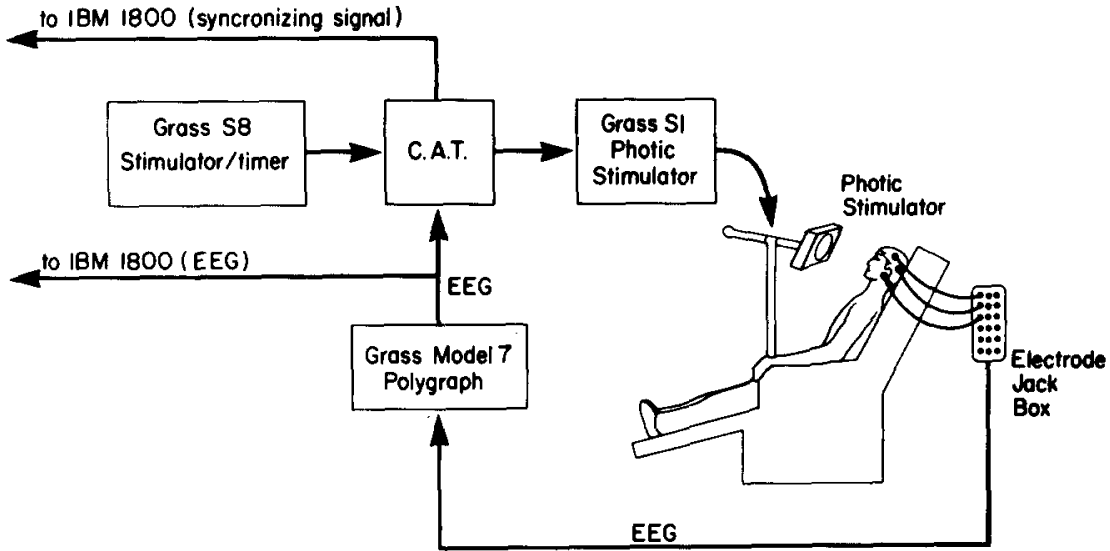

Fig. 1. Schematic diagram of the recording equipment. The Grass S8 stimulator/timer initiates a Mnemetron Computer of Average Transients (CAT) and an IBM 1800 computer. The CAT in turn drives the photostimulator, provides a timing signal, and can be utilized to provide X-Y plotting for immediate feedback. In addition, the output of the Grass polygraph is fed via an analog-to-digital converter to the IBM 1800 computer.

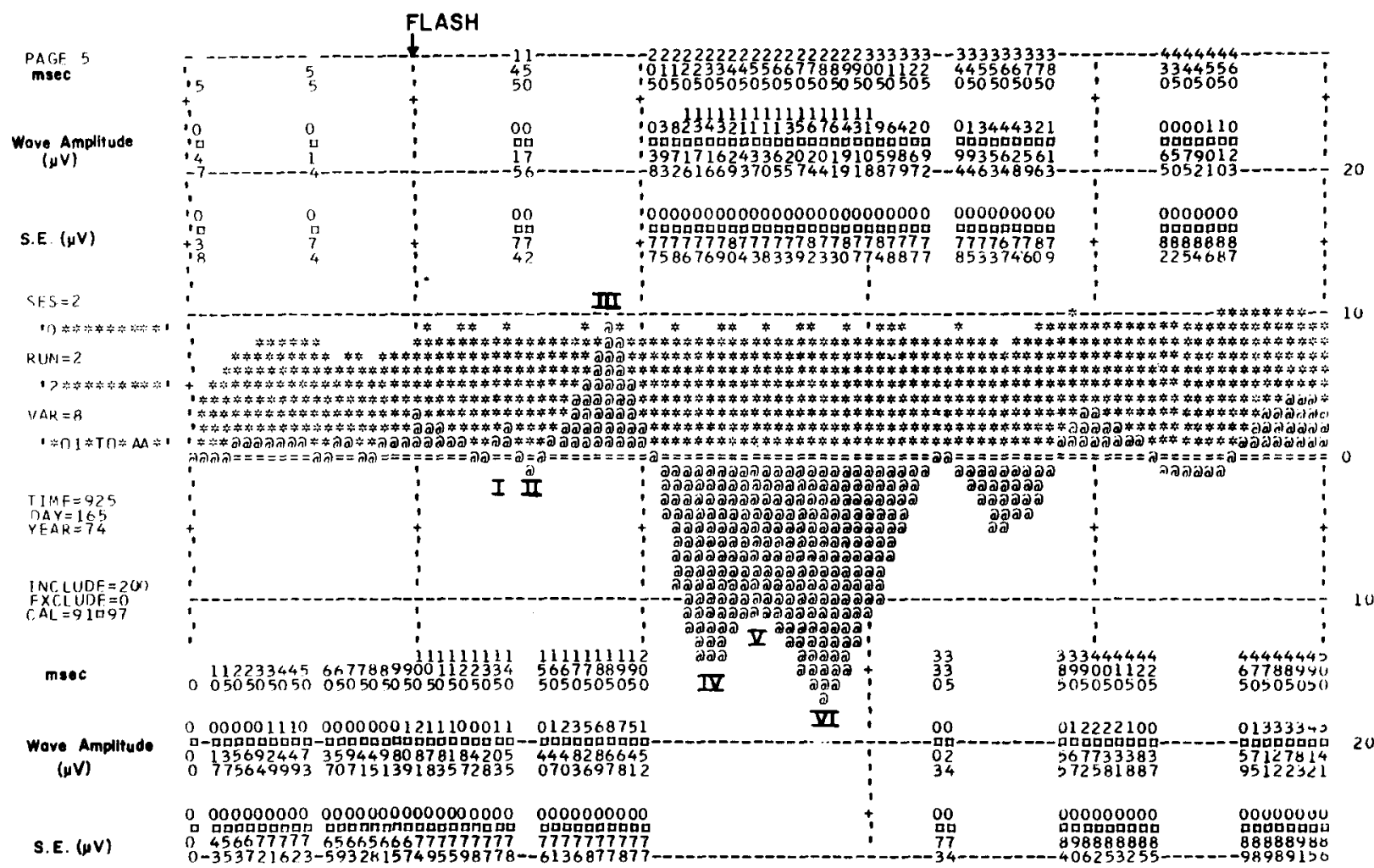

$2678 \mathrm{c}$

Fig. 2. Computer print-out of a VER. This figure represents the average of 200 flashes/evoked potentials randomized 1-3 sec with an analysis period of 500 msec. The flash occurred 100 msec into the analysis period, as shown at the arrow. 'At-signs' (@) indicate wave amplitude (negativity up), while asterisks (*) represent standard error (S.E.). In the left-hand margin are print-outs which designate the specific VER. The upper and lower group of numbers represent, from top to bottom, the analysis interval (msec), wave amplitudes $(\mu \mathrm{V})$ and S.E. ( $\mu \mathrm{V})$ as indicated. 
of the lamp with glass wool. Of course, the possibility does exist that a barely audible click caused a different response to flash in normals versus schizophrenic patients (Brazier 1964). However, no significant differences were found between the schizophrenic group and control group blind run records.

The EEG was monitored by a Grass Model 7 polygraph at a time constant of $0.24 \mathrm{sec}$ or $0.3 \mathrm{~Hz}$ and high bandpass of $35 \mathrm{~Hz}$. The evoked responses were summarized in combination with a Mnemetron Computer of Average Transients (CAT) and an IBM 1800 computer. In this setup, a Grass S8 drives a Mnemetron CAT, which in turn drives the photic stimulator, monitors the EEG, yields an X-Y plot for immediate feedback, and provides a synchronizing signal via an analogdigital converter to the 1800 computer. The 1800 is also monitoring the EEG, as well as receiving a 'synchronizing' signal from the CAT. A schematic diagram is shown in Fig. 1.

Results were tabulated from the IBM 1800 computer analysis of the data by a program which computes the mean and S.E. of any number of successive scans (200 responses) of a repetitive signal corrupted by stationary noise. The scan time may be selected at 1 , $0.5,0.25$, or $0.12 \mathrm{sec}$. A scan time of $0.5 \mathrm{sec}$ (500 msec) was used for this study. During each scan, the signal was sampled at 100 equally spaced intervals of $5 \mathrm{msec}$ each by a computer-controlled digital volt meter. The information from corresponding points of each of the 200 scans was averaged, and an estimate of the standard error of the average calculated for each sample run. The result was a combined graphical and numerical report which tabulated the mean and standard error of the microvolt signal at a given time (msec). A typical writeout is shown in Fig. 2.

\section{Results}

The latency ranges for the various waves of the occipital evoked potential were very similar to those of Kooi and Bagchi (1964). Nega- tive peak amplitudes for waves I, III, V and after-rhythm were included in the statistical analysis only if they were displayed above the isoelectric line by the computer as shown in Fig. 2. It should be noted that negativity was considered as being up. Positive peak amplitudes for waves II, IV and VI were included in the statistical analysis only if they were displayed below the isoelectric line by the computer. The central region $\left(\mathrm{C}_{3}\right.$ and $\left.\mathrm{C}_{4}\right)$ exhibited strong secondary waves with little or no primary waves being present as these are directly related to the occipital area of the brain. Therefore, the wave forms displaying the greatest positive, negative, positive amplitude combination were determined to be waves IV, V and VI, respectively. The next greatest negative wave preceding wave IV was considered to be wave III. In some cases it appeared that all the primary waves (I, II and III) were present in the central VER record and, therefore, were included in the statistical analysis.

Amplitudes for waves II and V were further analyzed by another set of criteria. The difference between the peak amplitude of wave I and the peak amplitude of wave II was considered to be the true peak amplitude of wave II and the difference between the peak amplitude of wave IV and the peak amplitude of wave $\mathrm{V}$ was considered to be the true peak amplitude of wave $\mathrm{V}$.

Group comparison Student $t$-tests were obtained from the means and standard errors obtained within each group. Significant scores are shown in Tables I and II for schizophrenic patients versus normals. Tables III and IV divide the schizophrenic patients into two subgroups based on whether they have HT or LT uptake levels (Gottlieb and Frohman 1974). The tryptophan uptake levels were done within a 1 month period of the VER. Significant scores are shown for HT versus LT uptake schizophrenics, and for HT and LT uptake schizophrenics compared to normals.

When the schizophrenics overall were compared to the normal controls (Tables I and II), no consistent, significant differences were ob- 


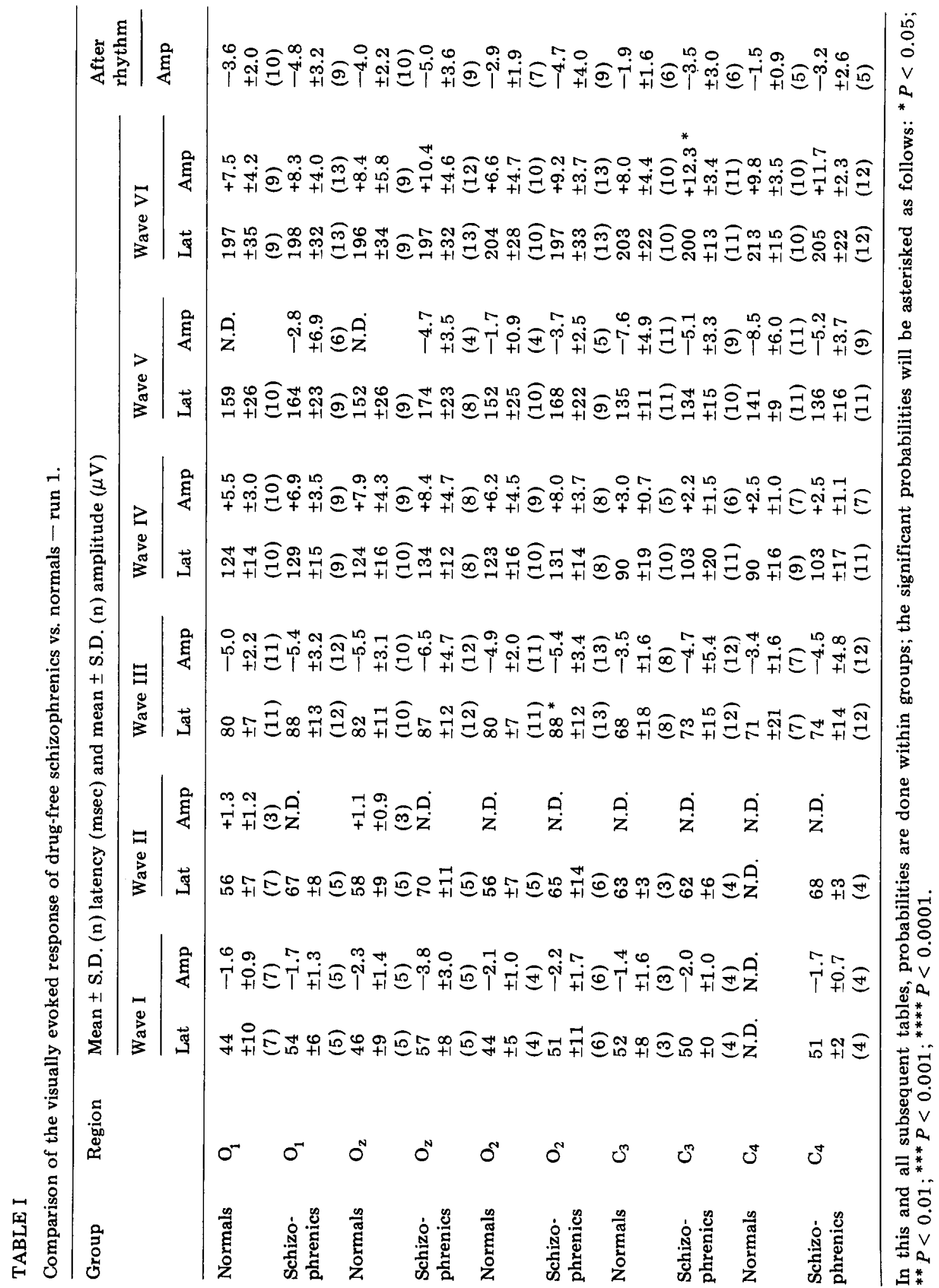




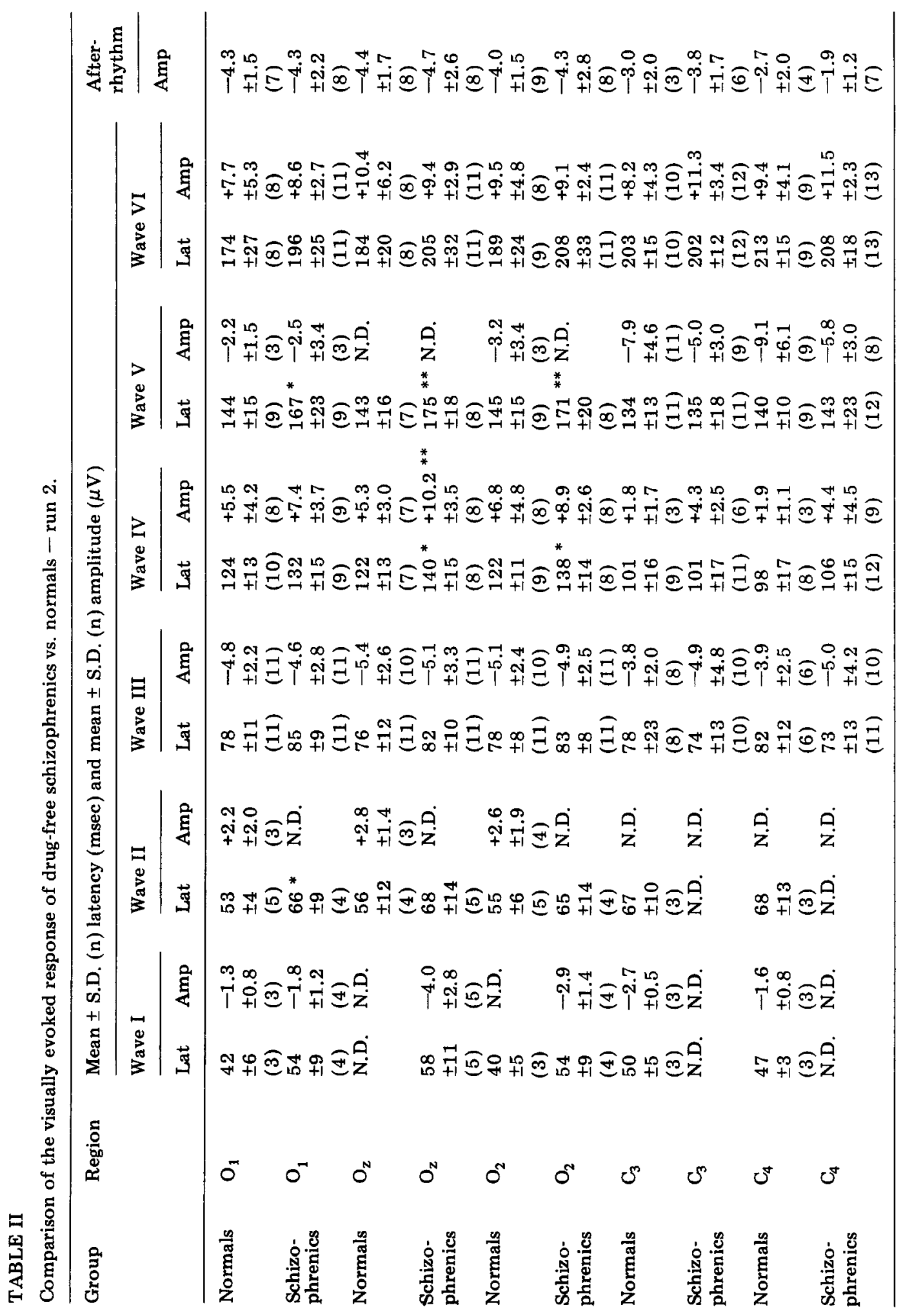




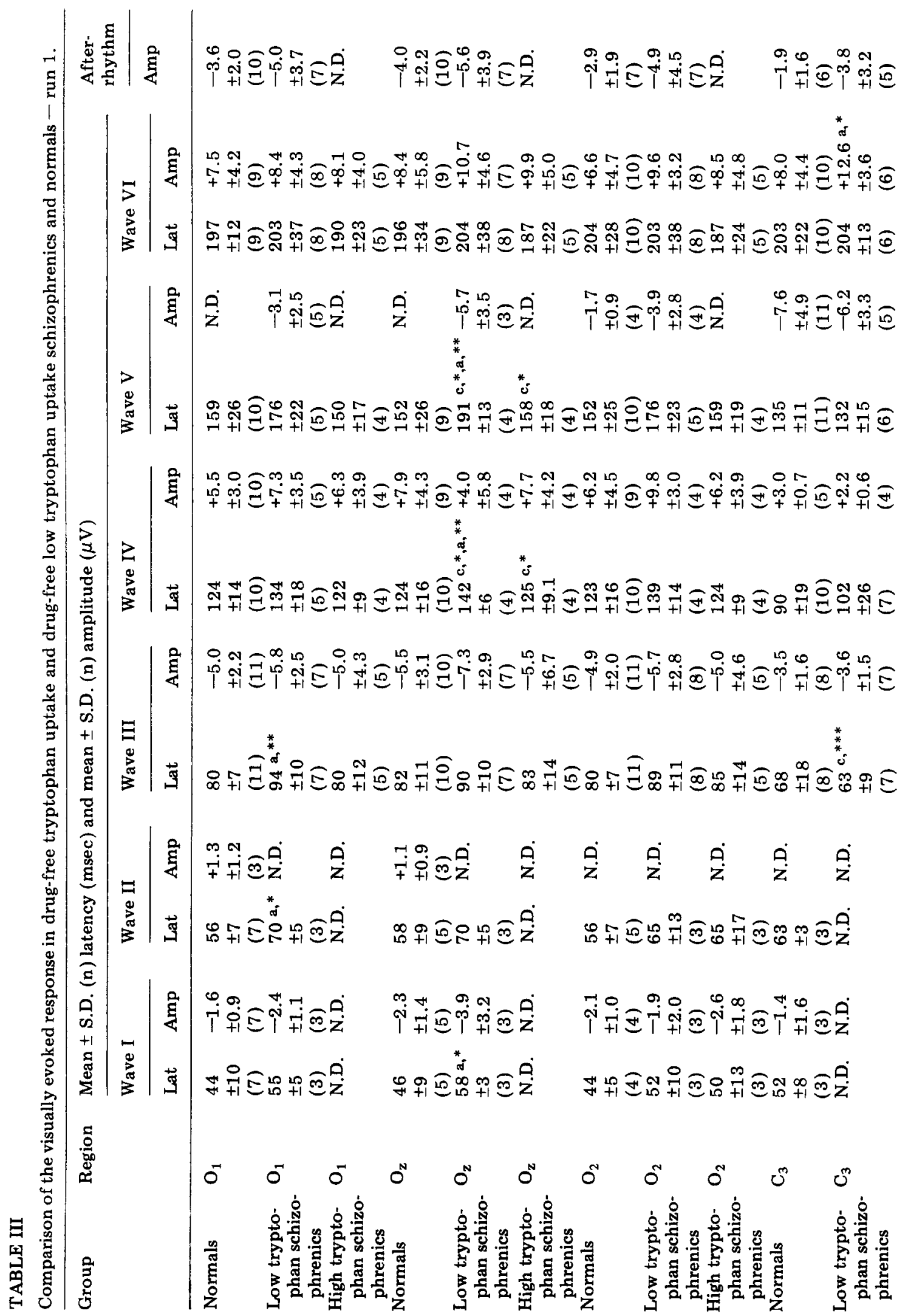




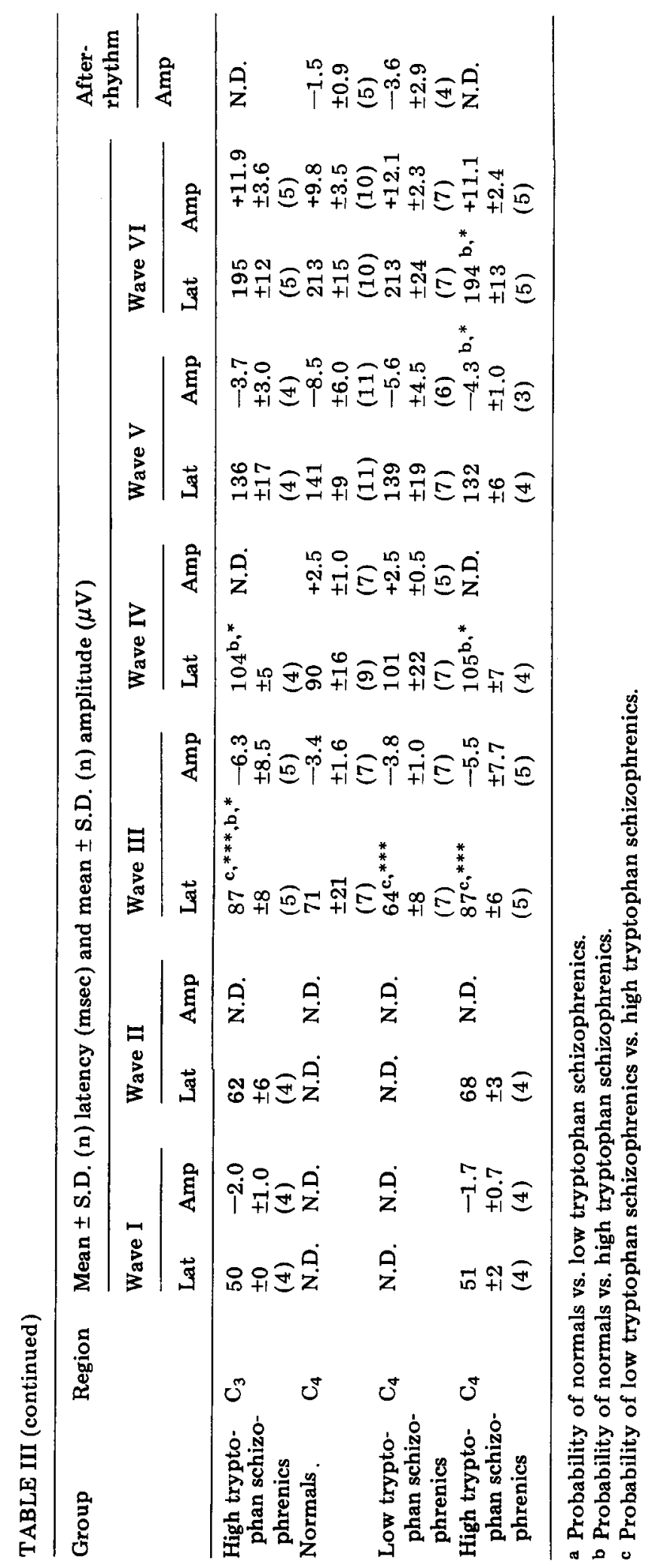




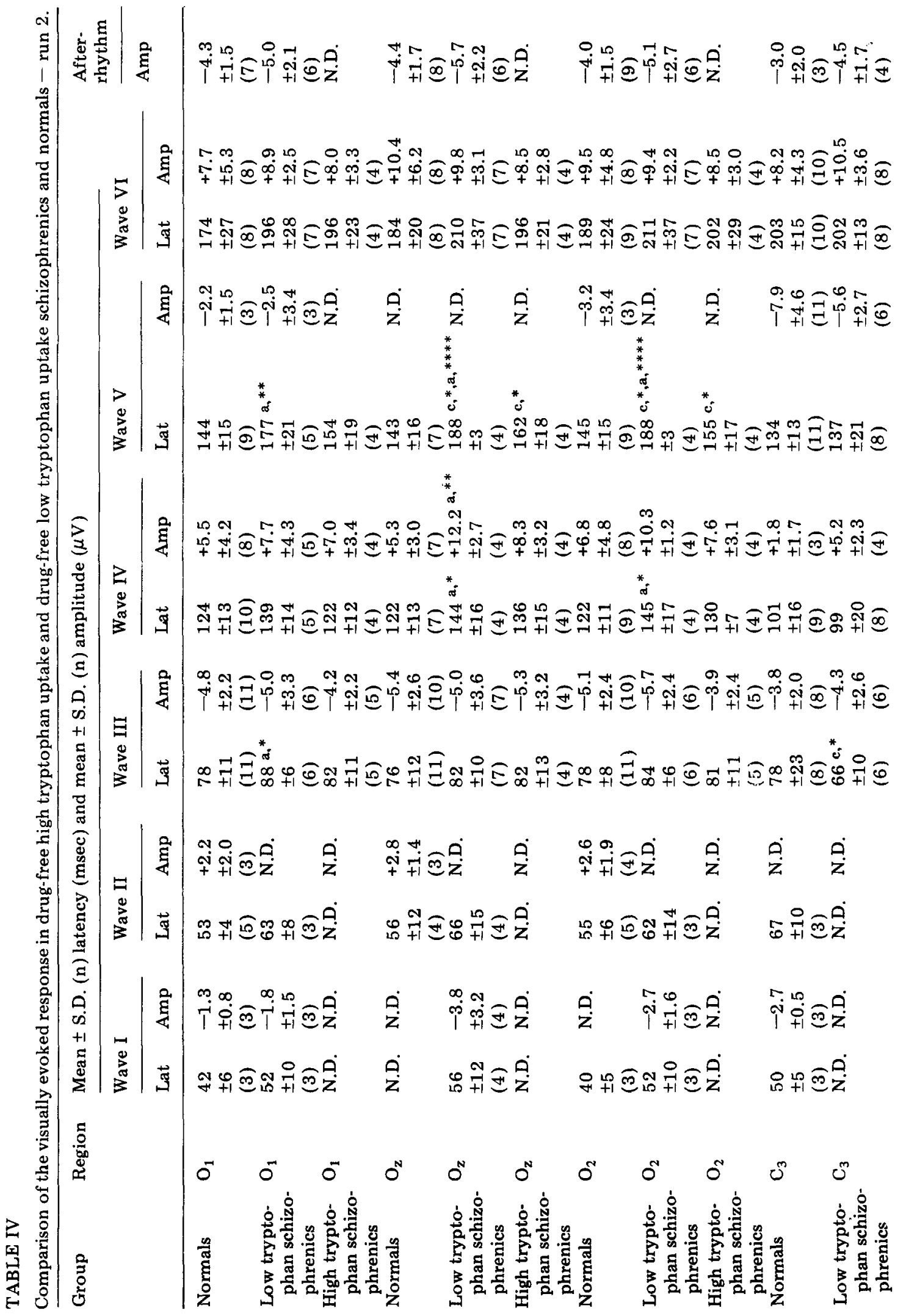




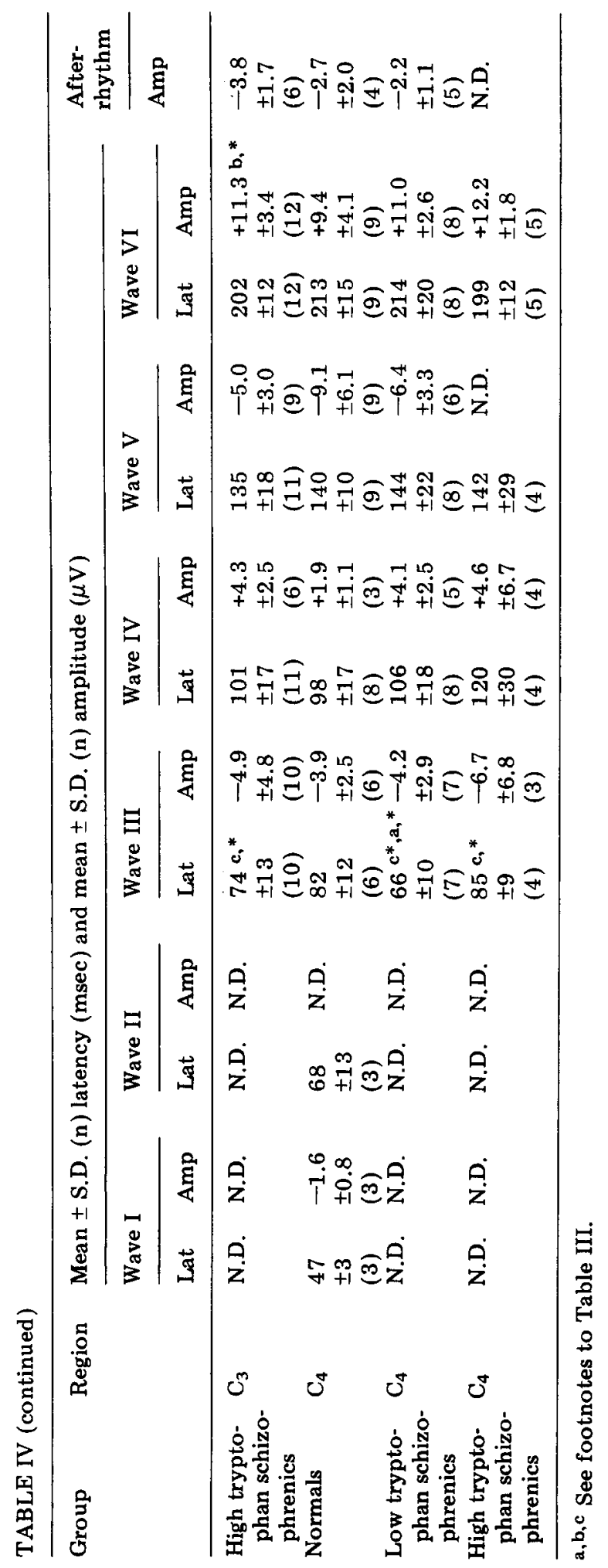


tained for the peak wave latencies or amplitudes of the VER either within each run or between run 1 and run 2 . It should be noted, however, that all the significant differences with respect to latency occurred within the occipital region with the schizophrenic patients showing a longer latency versus the normals.

\section{TABLE V}

Amplitude of wave II and wave $\mathrm{V}$ as distance traveled between two points.

\begin{tabular}{|c|c|c|c|c|}
\hline & \multicolumn{2}{|c|}{ Run 1 mean \pm S.D. (n) } & \multicolumn{2}{|c|}{ Run 2 mean \pm S.D. (n) } \\
\hline & Wave II amp & Wave $\mathrm{V}$ amp & Wave II amp & Wave $\mathrm{V}$ amp \\
\hline Normal $\mathrm{O}_{1}$ & $\begin{array}{l}1.4 \pm 1.3 \\
(7)\end{array}$ & $\begin{array}{l}-3.4 \pm 1.9 \\
(10)\end{array}$ & $\begin{array}{l}0.8 \pm 0.5 \\
(5)\end{array}$ & $\begin{array}{l}-2.5 \pm 1.7 \\
(10)\end{array}$ \\
\hline Schizophrenics $\mathrm{O}_{1}$ & $\begin{array}{l}0.8 \pm 0.5 \\
(6)\end{array}$ & $(9)$ & $\begin{array}{l}1.2 \pm 0.7 \\
(5)\end{array}$ & $-6.8 \pm 5.2^{a}{ }^{a} *$ \\
\hline High tryptophan $O_{1}$ & N.D. & $-3.3 \pm 3.1 \mathrm{~d}, *$ & N.D. & $-2.5 \pm 1.4 \mathrm{~d}^{* * *}$ \\
\hline Low tryptophan $\mathrm{O}_{1}$ & $\begin{array}{l}1.0 \pm 0.4 \\
(4)\end{array}$ & $\begin{array}{l}-10.4 \pm 4.8 \mathrm{~b}, * * \\
(5)\end{array}$ & $\begin{array}{l}1.0 \pm 0.6 \\
(4)\end{array}$ & $\begin{array}{ll}-11.0 \pm 3.6 & b, * * * \\
(4) & d, * *\end{array}$ \\
\hline Normal $\mathrm{O}_{z}$ & $\begin{array}{l}1.7 \pm 1.2 \\
(5)\end{array}$ & $\begin{array}{l}-2.9 \pm(2.8) \\
(10)\end{array}$ & $\begin{array}{l}1.5 \pm 0.5 \\
(4)\end{array}$ & $-3.1 \pm 2.8$ \\
\hline Schizophrenics $\mathrm{O}_{z}$ & $\begin{array}{l}1.0 \pm 0.8 \\
(4)\end{array}$ & $-7.6 \pm 4.9 \mathrm{a}^{*}$ & $\begin{array}{l}1.1 \pm 0.9 \\
(5)\end{array}$ & $\begin{array}{l}-6.6 \pm 5.3 \\
(8)\end{array}$ \\
\hline High tryptophan $\mathrm{O}_{z}$ & N.D. & $-3.2 \pm 2.3^{d, * * *}$ & N.D. & $-2.7 \pm 1.1 \mathrm{~d}, *$ \\
\hline Low tryptophan $\mathrm{O}_{\mathrm{z}}$ & $\begin{array}{l}1.2 \pm 0.8 \\
(3)\end{array}$ & $\begin{array}{l}-12.0 \pm 0.9 \mathrm{~b}, * * * * \\
(4)\end{array}$ & $\begin{array}{l}1.2 \pm 1.0 \\
(4)\end{array}$ & $\begin{array}{l}-10.6 \pm 4.7 \mathrm{~b}, * \\
(4)\end{array}$ \\
\hline Normal $\mathrm{O}_{2}$ & $\begin{array}{l}2.0 \pm 1.6 \\
(5)\end{array}$ & $\frac{-3.6 \pm 2.4}{(10)}$ & $\begin{array}{l}1.4 \pm 0.8 \\
(5)\end{array}$ & $\frac{-3.1 \pm(2.2)}{(10)}$ \\
\hline Schizophrenics $\mathrm{O}_{2}$ & $\begin{array}{l}0.7 \pm 0.4 \\
(6)\end{array}$ & $(8)^{7.6 \pm 5.5}$ & $\begin{array}{l}1.1 \pm 0.6 \\
(4)\end{array}$ & $\begin{array}{l}-6.8 \pm 6.3 \\
(8)\end{array}$ \\
\hline High tryptophan $\mathrm{O}_{2}$ & $\begin{array}{l}0.4 \pm 0.4 \\
(3)\end{array}$ & $-2.9 \pm 1.0 \mathrm{~d}, * * *$ & N.D. & $-2.4 \pm 0.9 \mathrm{~d}, *$ \\
\hline Low tryptophan $\mathrm{O}_{2}$ & $\begin{array}{l}1.0 \pm 0.4 \\
(3)\end{array}$ & $\begin{array}{ll}-12.4 \pm 3.1 & b, * * * * \\
(4) & d, * * *\end{array}$ & $1.0 \pm 0.7$ & $\begin{array}{ll}-11.2 \pm 6.4 & b_{,}^{*} \\
(4) & \end{array}$ \\
\hline Normal $C_{3}$ & $\begin{array}{l}1.2 \pm 0.6 \\
(3)\end{array}$ & $\begin{array}{l}-8.1 \pm 5.9 \\
(9)\end{array}$ & N.D. & $\begin{array}{l}-6.8 \pm 5.3 \\
(10)\end{array}$ \\
\hline Schizophrenics $\mathrm{C}_{3}$ & $\begin{array}{l}1.6 \pm 1.2 \\
(4)\end{array}$ & $\begin{array}{l}-5.6 \pm 3.2 \\
(9)\end{array}$ & N.D. & $\begin{array}{l}-4.5 \pm 2.7 \\
(10)\end{array}$ \\
\hline High tryptophan $\mathrm{C}_{3}$ & $\begin{array}{l}1.6 \pm 1.2 \\
(4)\end{array}$ & $\begin{array}{l}-4.9 \pm 2.2 \\
(3)\end{array}$ & N.D. & $\begin{array}{l}-5.4 \pm 1.9 \\
(3)\end{array}$ \\
\hline Low tryptophan $\mathrm{C}_{3}$ & N.D. & $-5.9 \pm 3.7$ & N.D. & $\begin{array}{l}-4.2 \pm 3.0 \\
(7)\end{array}$ \\
\hline Normal $\mathrm{C}_{4}$ & N.D. & $-8.4 \pm 6.3$ & $\begin{array}{l}1.5 \pm(1.5) \\
(3)\end{array}$ & $-7.8 \pm 6.0$ \\
\hline Schizophrenics $\mathrm{C}_{4}$ & $\begin{array}{l}1.7 \pm 0.9 \\
(4)\end{array}$ & $\begin{array}{l}-5.6 \pm 3.4 \\
(10)\end{array}$ & N.D. & $\begin{array}{l}-5.1 \pm 3.1 \\
(12)\end{array}$ \\
\hline High tryptophan $\mathrm{C}_{4}$ & $\begin{array}{l}1.7 \pm 0.9 \\
(4)\end{array}$ & $\begin{array}{l}-4.0 \pm 0.3 \\
(4)\end{array}$ & N.D. & $\begin{array}{l}-3.5 \pm 1.1 \\
(4)\end{array}$ \\
\hline Low tryptophan $\mathrm{C}_{4}$ & N.D. & $-6.7 \pm 4.1$ & N.D. & $-6.0 \pm 3.6$ \\
\hline
\end{tabular}

a Probability of all schizophrenics vs. normals.

b Probability of low tryptophan schizophrenics vs. normals.

c Probability of high tryptophan schizophrenics vs. normals.

d Probability of low tryptophan schizophrenics vs. high tryptophan schizophrenics. 
The patients were further split into $\mathrm{HT}$ and LT subgroups (Tables III and IV). No consistent significant differences were observed in the peak wave amplitudes of the subgroups either between themselves or when compared to normals. However, in the peak latencies of the occipital region, what was significantly different in Tables I and II for waves IV, V and VI is also significantly different in the LT subgroup versus normals. Interestingly, all the significant LT latencies ran longer when compared to normals. Eight of the 9 significant differences for the LT subgroup versus normals occur in the occipital region with wave $\mathrm{V}$ showing differences in all the occipital leads $\left(\mathrm{O}_{1}, \mathrm{O}_{\mathrm{z}}\right.$ and $\left.\mathrm{O}_{2}\right)$.

The HT group showed no significantly different peak latencies when compared to normals in the occipital region. When the significant data from Tables I to IV are combined for latency, waves III, IV and V in the occipital regions show the greatest variability while wave III in the central regions shows only a significant difference in the HT versus $\mathrm{LT}$ subgroups.

Since run 2 showed more and greater significant differences (Tables II and IV, respectively) from run $1, t$-tests were determined between both runs for all groups. No significant differences were found between the two runs for any group.

The amplitudes of wave II and wave V were further analyzed by taking the difference $(\mu \mathrm{V})$ between waves I and II and waves IV and $V$. The results are shown in Table $V$. No significant differences were found in wave II; however, in wave $\mathrm{V}$ for the occipital regions, the LT group showed significant increase amplitudes when compared to either normals or the HT subgroup. No significant differences were seen in the central region for the LT subgroup. The HT subgroup showed no consistent significant differences for either the occipital or central regions.

As one reviews the data from the occipital region in all the tables it appears that the peak wave latencies of all the schizophrenics and the LT subgroup consistently run longer than the normals. The LT subgroup peak wave latencies also run longer than the HT subgroup. Furthermore, the amplitude peaks of waves IV and $V$ and to a lesser extent wave VI in the occipital region do tend to be increased in the schizophrenic and LT subgroups when compared to normals. The LT subgroup also displays greater variability over the HT subgroup. There were no consistent patterns in the central region for either wave peak amplitudes or latencies except for the wave IV peak latency of the HT schizophrenics which ran longer in both runs versus LT. It should be noted that no significant differences were seen in either the occipital or central regions for the after-rhythm.

The two psychological testing scales, the BPRS and ward token system for the schizophrenic patients correlated significantly. The BPRS scores were further divided into the HT and LT subgroups. The HT group had a higher BPRS score of $38 \%$ indicating a greater degree of psychopathology than the LT patients, which had a score of $24 \%(P<0.05)$.

\section{Discussion}

In this study the VER of chronic schizophrenics showed no consistent significant differences when compared to normals. However, the differences, which did occur, occurred mainly in the occipital brain region with the schizophrenic VER displaying prolonged latencies and increased amplitudes. Therefore, this study overall does not provide any electrophysiological evidence for an indole hallucinogen hypothesis for process schizophrenia.

The patients were further divided into high and low plasma tryptophan uptake levels since it is hypothesized that tryptophan $\rightarrow$ tryptamine $\rightarrow$ N,N-dimethyltryptamine (DMT), a known hallucinogen. From the BPRS scores HT schizophrenics appear to have a greater degree of psychological disturbances when compared to the LT schizophrenics. Caldwell and Domino (1967) found 
HT schizophrenics spend less time in stage IV sleep (the deepest stage) relative to controls. The HT group also exhibits much poorer proprioception (Rosenbaum et al. 1965) and galvanic skin response conditioning (Frohman 1971) relative to normals. Therefore, it would follow that the HT schizophrenics would have a diminished VER amplitude in support of the indole hypothesis.

Although the HT schizophrenics did show a diminished VER amplitude when compared to the LT schizophrenics, no significant differences were found between the HT schizophrenics and normal controls. Our failure to find any difference in the VER amplitude of the HT schizophrenics versus normals could be related to the fact that these patients were a select group of non-responders with long histories of illness. Small and Small (1965), in their review of schizophrenic EEGs, reported that the longer the period of illness the more normal the EEG recordings. Furthermore, since these patients were hospitalized on the average of 9 years, the possibility does exist that over time they developed tolerance to an indole hallucinogen such as DMT. Tolerance has been observed to DMT in rats (Kovacic and Domino 1976).

The fact that the LT schizophrenic group as well as schizophrenics overall displayed prolonged latencies and increased amplitudes when compared to normals further suggests that the schizophrenics, and to a greater degree the LT schizophrenics, do not possess an excess of any indole-containing hallucinogen. This study in general confirms that of Rodin (1971) who studied a similar group of schizophrenic patients.

\section{Summary}

Thirteen cooperative male drug-free chronic schizophrenic patients, and 11 mentally normal male controls were studied. The VER was recorded from scalp leads $\mathrm{O}_{1}, \mathrm{O}_{2}$, $\mathrm{O}_{2}, \mathrm{C}_{3}$ and $\mathrm{C}_{4}$ to combined ear reference $\left(A_{1}-A_{2}\right)$. The stimulus was an unpatterned flash of single intensity. Compared to normal controls, there were no consistent differences in wave peak latencies or amplitudes for chronic schizophrenics in any brain area tested. When the chronic schizophrenic patients were separated on the basis of high and low tryptophan uptake, using the Frohman-Gottlieb criteria, the high uptake group exhibited normal VERs while in the occipital regions the low tryptophan uptake group exhibited prolonged latencies and an increased amplitude for wave $\mathrm{V}$ when compared to normals. From BPRS scores the high tryptophan subgroup irıdicated a greater degree of psychopathology than the low tryptophan subgroup. The results obtained do not support an indole hallucinogen hypothesis for process schizophrenia.

\section{Résumé}

Comparaison des réponses évoquées visuelles (PEVs) de malades schizophrènes chroniques sans traitement et de sujets normaux de contrôle

Treize patients coopératifs, de sexe masculin, schizophrènes chroniques sans traitement et 11 sujets de contrôle normaux, du même sexe, ont été étudiés. Les PEVs ont été enregistrés sur le scalp par des dérivations monopolaires situées en $\mathrm{O}_{1}, \mathrm{O}_{2}, \mathrm{O}_{2}, \mathrm{C}_{3}$ et $\mathrm{C}_{4}$, avec référence sur les deux oreilles reliées entre elles. Le stimulus était un flash simple, d'intensité constante. Aucune différence significative n'a été observée dans les latences ou les amplitudes des composantes des PEVs, pour aucune des topographies étudiées, entre les sujets schizophrènes et les sujets de contrôle. Lorsque l'on sépare les malades en deux groupes sur la base d'une capture élevée ou faible de tryptophane, en utilisant le critère de Frohman-Gottlieb, le groupe à capture élevée montre des PEVs normaux, tandis que, dans les régions occipitales, le groupe à capture faible présente des latences allongées et un amplitude augmentée de l'onde $V$ par rap- 
port à la normale. D'après les scores au BPRS, le groupe à capture élevée de tryptophane présente un plus grand degré de morbidité que le groupe à capture faible. Les résultats obtenus ne confirment pas l'hypothèse d'un facteur indol hallucinogène, dans les schizophrénies processuelles.

The authors would like to thank Mr. George Hovey, for the computer program; Ms. Kathleen Lennox for the statistical analysis; and Mr. Samuel Wasson for design and setup of the electronic equipment interfaces.

\section{References}

Brazier, M.A. A study of the variability of response to flicker: the influence of other sensory stimuli. Docum. ophthal. (Den Haag), 1964, 18: 221-237.

Caldwell, D.F. and Domino, E.F. Electroencephalographic and eye movement patterns during sleep in chronic schizophrenic patients. Electroenceph. clin. Neurophysiol., 1967, 22: 414-420.

Ciganek, L. The EEG response (evoked potential) to light stimulus in man. Electroenceph. clin. Neurophysiol., 1961, 13: 165-172.

Cooper, R., Osselton, J.W. and Shaw, J.C. EEG Technology. Butterworth, London, 1971.

Domino, E.F., Demetriou, S., Tuttle, T., Lennox, K. and Klinge, V. Comparison of the visually evoked response in drug free chronic schizophrenic patients and normal controls. Joint Meeting of the American Electroencephalographic Society and American Epilepsy Society, 30th Annual Meeting, September 29, 1976, p. 43 (Abstract).

Evarts, E.V. Effects of a series of indoles on synaptic transmission in the lateral geniculate nucleus of the cat. In: H.H. Pennes (Ed.), Psychopharmacology: Pharmacological Effects on Behavior (No. III, Progress in Neurobiol.). Hoeber-Harper, New York, 1958: 173-202.

Frohman, C.E. Biochemical mechanisms. In: G. Tourney and J.S. Gottlieb (Eds.), The Lafayette Clinic Studies on Schizophrenia. Wayne State University Press, Detroit, Mich., 1971: 125-161.

Goldstein, L., Murphree, H.B., Pfeiffer, C.C., Sugerman, A.A. and Jenney, E.H. Quantitative electroencephalographic analysis of naturally occurring (schizophrenic) and drug-induced psychotic states in human males. Clin. Pharmacol. Ther., 1963, 4: $10-21$

Goldstein, L., Sugerman, A.A., Stolberg, H., Murphree, H.B. and Pfeiffer, C.C. Electrocerebral activity in schizophrenics and non-psychotic sub- jects: quantitative EEG amplitude analysis. Electroenceph. clin. Neurophysiol., 1965, 19:350.

Gottlieb, J.S. and Frohman, C.E. The biochemistry of schizophrenia. In: S. Arieti and E.B. Brody (Eds.), American Handbook of Psychiatry, Vol. III, Adult Clinical Psychiatry. Basic Books, New York, 1974: 601-626.

Hall, R.A., Rappaport, M., Hopkins, H.K. and Griffin, R.B. Peak identification in visual evoked potentials. Psychophysiology, 1973, 10: 52-60.

Itil, T.M. Qualitative and quantitative EEG findings in schizophrenia. Schizophrenia Bull., 1977, 3: $61-79$.

Itil, T.M., Saletu, B. and Davis, S. EEG findings in chronic schizophrenics based on digital computer period analysis and analog power spectra. Biol. Psychiat., 1972, 5: 1-13.

Kooi, K.A. and Bagchi, B.K. Observations on early components of the visual evoked response and occipital rhythms. Electroenceph. clin. Neurophysiol., 1964, 17: 638-643.

Kovacic, B. and Domino, E.F. Tolerance and limited cross-tolerance to the effects of N,N-dimethyltryptamine (DMT) and lysergic acid diethylamide25 (LSD) on food-rewarded barpressing in the rat. J. Pharmacol. exp. Ther., 1976, 197: 495-502.

Moore, R.H., Hatada, K. and Domino, E.F. Effects of $\mathrm{N}, \mathrm{N}$-dimethyltryptamine on electrically evoked responses in the cat visual system and modification by neuroleptic agents. Neuropharmacology, 1976, 15: 515-539.

Murphree, H.B., Jenney, E.H. and Pfeiffer, C.C. Quantitative electroencephalographic analysis of the effects of lysergic acid diethylamide (LSD-25) and D-amphetamine in man. Fed. Proc., 1962, 21 : 337.

Rodin, E.A. Electroencephalographic studies in schizophrenic patients. In: G. Tourney and J.S. Gottlieb (Eds.), The Lafayette Clinic Studies on Schizophrenia. Wayne State University Press, Detroit, Mich., 1971: 263-293.

Rodin, E.A. and Luby, E. Effects of LSD-25 on the EEG and photic evoked responses. Arch. gen. Psy. chiat., 1966, 14: 435-441.

Rodin, E.A., Grisell, J. and Gottlieb, J. Some electrographic differences between chronic schizophrenic patients and normal subjects. In: J. Wortis (Ed.), Recent Advances in Biological Psychiatry, Vol. X. Plenum Press, New York, 1968: 194-204.

Rosenbaum, G., Flenning, F. and Rosen, H. Effects of weight intensity on discrimination thresholds of normals and schizophrenics. J. abnorm. soc. Psychol., 1965, 70: 446-450.

Shagass, C. Evoked Brain Potentials in Psychiatry. Plenum Press, New York, 1972.

Shagass, C. EEG and evoked potentials in the psychoses. In: D.X. Freedman (Ed.), Biology of the Major Psychoses: a Comparative Analysis. Raven 
Press, New York, 1975: 101-128.

Shagass, C. An electrophysiological view of schizophrenia. Biol. Psychiat., 1976, 11: 3-30.

Shagass, C. and Schwartz, M. Visual evoked response characteristics in a psychiatric population. Amer. J. Psychiat., 1965, 121 : 979.

Shagass, C. and Straumanis, J.J. Drugs and human sensory evoked potentials. In: M.A. Lipton, A. DiMascio and K.F. Killam (Eds.), Pyschophar- macology: a Generation of Progress. Raven Press, New York, 1978: 699-709.

Shagass, C., Straumanis, Jr., J.J., Roemer, R.A. and Amadeo, M. Evoked potentials of schizophrenics in several sensory modalities. Biol. Psychiat., 1977, 12: $221-235$.

Small, J.G. and Small, I.F. Re-evaluation of clinical EEG findings in schizophrenia. Dis. nerv. Syst., 1965, $26: 345-349$. 